\title{
E-MATHEMATICS: PRE-INSTRUCTIONAL AND SUPPLEMENT INSTRUCTION AND THEIR IMPACT OF STUDENT'S ONLINE PARTICIPATION AND FINAL EXAM SCORE
}

\author{
Richard Ng (richard_ng@oum.edu.my) \\ Abtar Kaur (abtar@oum.edu.my) \\ Siti Farina Sheikh Mohamed (sitifarina@oum.edu.my) \\ Latifah Abdol Latif (latifah@oum.edu.my) \\ Ramli Bahroom (ramli@oum.edu.my) \\ Open University Malaysia
}

\begin{abstract}
Open University Malaysia (OUM), Malaysia's first open and distance learning with over 70.000 students, offers more than 51 programs to-date. More than $90 \%$ of its students are working adults who are unable to leave their jobs or families behind to pursue their dream of getting a degree. The blended learning approach adopted by OUM provides the flexibility for working adult's to obtain the required paper qualification and to upgrade their knowledge. One of the important elements of blended learning is the use of online discussion forum where learning takes place beyond classroom. Mathematics, a traditionally difficult course, forms part of the prerequisite for students to obtain a business degree at OUM. The adult learners at OUM generally have left school for at least five years and most of them have low grades in Mathematics at $O^{\prime}$ Level. Thus it is a big challenge for these adult learners to undertake a Mathematics course via online with minimum Face-to-Face contact with their tutors. This paper focuses on the implementation of pro-instruction workshop and supplemental instruction to find its impact on student's online participation and exam results of 88 students. The contents of the online forum were also analyzed using a 34-item instrument derived from the Community of Inquiry model. Results obtained showed that there was a strong correlation between workshop participation and final exam score. Independent samples t-test conducted showed that there was a significant difference between the mean score of online discussion ratio and final examination between participants attached to a tutor conducting the workshop and extended coaching compared to participants attached to another tutor using the normal teaching guide. The means $\mathrm{COI}$ score obtained for mathematics between the two tutors indicated that there is a difference in the teaching and cognitive presence but almost similar in the social presence.
\end{abstract}

Key words: community of inquiry, mathematics, online participation, pre-instruction, supplemental instruction.

The online discussion forum is one of the three key components of a blended learning pedagogy used at Open University Malaysia (OUM), Malaysia's first open and distance learning university with over 70,000 students who are mostly working adult. Known as MyLMS, 
the online discussion forum enables learning to be expanded beyond classroom without barriers of space and time. Learners are given a maximum of five marks for their online participation based on a rubric where 3 marks are allocated for quality posting and 2 marks for quantity.

For a working adult who has left school for more than five years, coming back to school to take up math course is a big challenge, what more if he/she has to do it via blended pedagogy with minimum contact hours. Math has traditional been regarded as a very difficult subject. The situation becomes worse when learners find difficulties in posting their problems via MyLMS as the system does not support mathematical symbols and that they are not familiar with software that support mathematical symbols. Some of these learners may also be hampered by technological problems due to their incompetence in handling the computer and Internet. Hence the grade of these learners will he affected and this may impact on their intention to stay in their programs.

In order to arrest these problems, OUM has embarked in a pre-instructional workshop aimed at providing basic foundation in math to learners who will be taking up the math course. Participation of the workshop however is not compulsory. Learners will also be taught on how to access the MyLMS as well as handling the Microsoft Equation Editor software during the workshop, which can help them type mathematical symbol for online discussion. Learners undergoing math course will also be guided via online supplemental instruction where questions will lie posted and certain learners who are good at math will provide solutions and explanations facilitated by their tutors.

This Paper investigated the impact of the pre-instructional workshop and supplemental instructions on learners' online participation ratio, final score, online participation pattern and Community of Inquiry (COI) score of 88 learners attached to tutors.

As Open and Distance Learning mode is gaining popularity, there are many comparative studies conducted over the last few years. Russell $(2001,2005)$ in his research opined that there is no significant difference between learning that lakes place to a traditional environment versus distance education. This was supported by Neuhauser (2002) who found that course delivery media was not sufficiently significant to affect course outcomes. Tatum (2000) in his $A B C$ Theory (Affirm identity, Build community and Cultivate leadership) opined that every learner in a learning environment needs a supportive climate of achievement.

Many believe that technical subjects including mathematics cannot be delivered $100 \%$ via online. According to Engelbrecht and Harding (2004), this could be due to the inability of the Internet Hypertext Markup Language (HTML) to represent mathematical symbols and also the general belief that mathematics can only be taught successfully via face-to-face approach. Mathematics has been regarded by learners historically as one of the many difficult courses or "high-risk" courses due to its low success rate in completion.

Weems (2002) conducted a comparative study on the Introductory Algebra subjects offered to two groups of students: one taught via online and the other via traditional approach. He found 
that there is no significant difference between the achievements of both groups of students. $A$ similar research conducted by Ryan (2001) on the Introductory Mathematics subject also yielded the same result. However, Russell (2006) found that there is a significant difference between the final grades for the Introductory Mathematics course for online and traditional students and that the mean grade for online students are lower than the mean grade of traditional format students.

Lotze (2002), in his comparative study on the teaching of mathematics and statistics via faceto-face and online, found that students in the online learning mode not only struggle with the mathematics concept but also hampered by the use of mathematical symbols, which is necessary to understand and explain the concept. Thus, it is important to introduce both the basic concepts of mathematics and how to use software such as Microsoft Equation Editor to communicate these symbols to beginners, especially adult learners.

Math has been regarded by learners historically as one of the many difficult courses or "highrisk" courses due to its low success rate in completion. Many learners are not prepared for higher level of studies and do not know how to study (Martin \& Arendale, 1993). According to Hodges (2001), institutions now turn to supplemental instruction (SI), one of two forms of academic assistance besides tutoring to help students succeed in their studies. The education innovative SI was developed by Deanna Martin in 1973 at the University of Missouri in Kansas City. Many researches conducted on SI have shown significant results where it does influence grades and even retention (Phelps, 2005 \& Duty, 2003).

According to Lotze (2002), adult learners returning for academia after a long absence often experience high level of discomfort with technology. Thus, many Online Distance Learning (ODL) institutions introduced orientation programs to improve on their learners' readiness in ODL learning. According to Pillay, Irving and Tones (2007), many institutions that adopt online learning have very little regard on pre-requisite personal and technicalities required by students for academic achievement and satisfaction, which are predictors of retention. Though the level of technical skills with regard to using and navigating in online learning does not directly affect students' achievement, they do influence their engagement with technology. Thus many ODL institutions introduced orientation programs to improve on their learners' readiness in ODL learning.

SI offered via online can become a tool for collaborative learning experience. COI model provides a means to study online learning and teaching to find out if collaborative learning is achieved. According to Garrison, Anderson and Archer (2000), the key component of COI is collaboration with regard to engaging students in an online learning environment. He suggested that a sense of community time to form but once it is formed; it will become a powerful learning catalyst and support for the learning community. Creating and sustaining this community is framed by the three core elements of a community of inquiry: social presence, cognitive presence, and teaching presence. See Figure 1. 


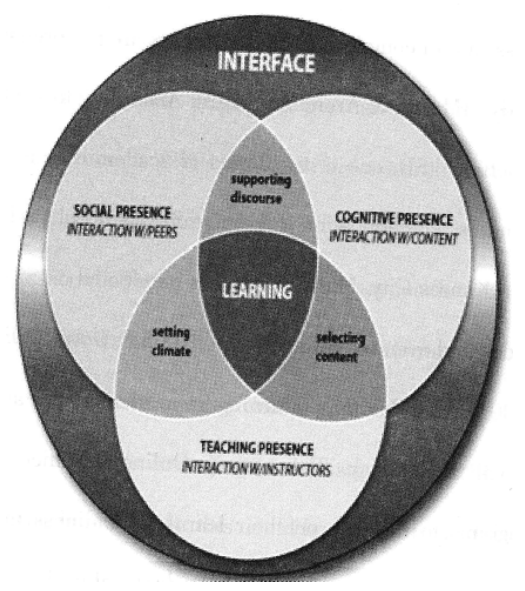

Figure 1. The Community of Inquiry Model (Garrison, Anderson, \& Archer, 2000)

Garrison, Anderson and Archer (2000) opined that online learning occurs through the interaction of three domains; Social Presence, Cognitive Presence and Teaching Presence.

- Social presence reflects the ability to connect with meaning community of learners on a personal level.

- Cognitive presence is the process of constructing meaning through collaborative inquiry.

- Teaching presence is the crucial integrating force that structures and leads the educational process in a constructive, collaborative and sustained manner.

Abtar (2004) noted that students' participation is often minimal without an instructor's participation. She suggested that planned, focused and guided online discussion can result in successful learning experience. Providing feedback especially encouraging comments, pointing out errors and correcting them and using leading questions in an online discussion helps in guiding and directing students to follow and continue their posting. She added that providing timely feedback is important as questions posted by students left unanswered for too long will discourage posting.

The SI concept, which involves face-to-face coaching by experienced learners, can be expanded into online forum with proper software and coaching and turned into a collaborative learning experience. $\mathrm{Ng}$ and Wagner (2007) in their research found that the participation of learners increased to $84 \%$ from 64\% (Abtar, 2004) with the introduction of Collaborative Online Learning (COL). The learner's average hit rate is generally higher for $\mathrm{COL}$ courses compared to non-COL courses. Fadzil (2005) has proposed five critical success factors in developing online learning, one of which is the human factor-by developing a new learning culture where learning must be learner centered, interactive and engaged in a collaborative online learning.

Collaborative learning brings participants together in some kind of social interaction where they feel they are more involved and thus learns more effectively. Online tutors play an important role in reassuring learners the support, making learners feel they have a good rapport with their tutors and that they are being assessed and guided (Hofmann. 2004). 
$\mathrm{Ng}$ (2008) in his research on tutors and learner's participation in the online discussion forum found that most of the posting made for mathematics course happened during the first four weeks of participation and gradually reduced from midway toward the end of the course. He opined that such behavioural pattern is due to technological barriers faced by both tutors and learners. For COL to take place in expanding teaching of mathematics into online, learners and tutors must he equipped with the technological know-how as well as some basic foundations in that subject.

\section{METHODS}

88 learners attached to two tutors (Tutor $\mathrm{R}$ and Tutor $\mathrm{S}$ ) were involved in the research. Apart from the normal tutorial session, Tutor $\mathrm{R}$ was also involved in carrying out the online $\mathrm{SI}$ whereas Tutor $S$ involved in just carrying out the normal tutorial session based on the standard module supplied.

The workshop was held two weeks before the start of the first tutorial. The contents of the workshop are presented in Table 1. At the end of each session, participants are required to answer questions related to the topic as part of the group activity and present the solutions.

Table 1. Structure of the Pre-Instructional Workshop

\begin{tabular}{cl}
\hline Session & \multicolumn{1}{c}{ Workshop Content } \\
\hline 1 & Overview on ODL Concepts of Learning: Goal-setting, Successful Learning Strategies, Time \\
& Management and Tips for Improving Mathematic \\
3 & Basic Mathematics involving Numbers-Group Presentation 1 \\
4 & Basic Algebra-Group Presentation 2 \\
5 & Indices and Logarithms-Group Presentation 3 \\
\hline
\end{tabular}

The research continued throughout the whole semester where learners attached to tutor $R$ were provided with additional supplement coaching $(\mathrm{SI})$ via online and tutor $\mathrm{S}$ only provided normal face-to-face coaching as per lesson guide. At the end of the semester, the online participation ratios of all the learners were obtained by dividing the number of messages posted in the online discussion forum with their online participation marks. The final exam score of these learners were also recorded.

The number of hits made by the learners and tutors in the online discussion forum were recorded and tabulated using Microsoft Excel to create a chart so as to determine the pattern of participation. The contents of the online discussion forum of these learners and tutors were analyzed using a 34--item COI questionnaire based on a 5-point Likert scale in order to find the mean score for social presence, teaching presence and cognitive presence.

The independent samples t-test was used to compare the means of online participation ratio and final examination score for participants of workshop for tutor $\mathrm{R}$ and tutor $\mathrm{S}$ to see if there was significant difference between the two groups or was it due to random error. 


\section{RESULTS AND DISCUSSION}

\section{Sample}

Out of the 88 learners invited to attend the pre-instructional workshop only 22 turned up, of which, 10 of them were tutored by Tutor $\mathrm{R}$ and 12 by tutor $\mathrm{S}$. Please refer Table: 2

Table 2. Samples Distribution

\begin{tabular}{cccc}
\hline \multirow{2}{*}{ Tutor } & \multicolumn{2}{c}{ Participation in the Workshop } & \multirow{2}{*}{ Total } \\
\cline { 2 - 4 } & Yes & No & 52 \\
$\mathrm{R}$ & 10 & 42 & 36 \\
$\mathrm{~S}$ & 12 & 24 & 88 \\
\hline Total & 22 & 60 & \\
\hline
\end{tabular}

1. Was there a significant difference in the online participation ratio between learners who have participated in the pre-instructional workshop and learners who have not?

Table 3 shows the mean ratio of learner attached to tutor $R$ and $S$ who have participate in the workshop and also who have not participated in workshop. Generally it can be noted that the mean ratio of online participation of learner who attended the workshop is higher than those who have not attended the workshop. Learners attached to Tutor $R$ and participated in the workshop have a mean ratio of 25.630 compared with learners who have not participated in the workshop with a mean ratio of 10.979. Learners attached to Tutor S and have participated in the workshop have an online participation mean of 3.017 compared to those who have not participated with a mean score of 1.750 .

Table 3. Mean Score of the Online Participation Ratio of Learners Who Have Participated in the Pre-instructional Workshop and Learners Who Have Not

\begin{tabular}{cccccc}
\hline Tutor & Participation Status & $\mathrm{N}$ & Mean Ratio & Std. Deviation & Std. Error Mean \\
\hline \multirow{2}{*}{$\mathrm{R}$} & Yes & 10 & 25.630 & 17.582 & 5.560 \\
& No & 42 & 10.979 & 7.961 & 1.228 \\
$\mathrm{~S}$ & Yes & 12 & 3.107 & 1.869 & 0.540 \\
& No & 24 & 1.750 & 1.101 & 0.225 \\
\hline
\end{tabular}

Table 4 shows the result of Independent Sample T test carried out on the Online Participation Ratio. The results show that both learners attached to Tutor $\mathrm{R}$ and Tutor $\mathrm{S}$ who have attended the workshop have an alpha value of less than 0.05 indicating that there is a significant difference in the online participation ratio between those who have attended the workshop and those who have not. 
Table 4. Independent Sample T Test Carried Out on Online Participation Ratio for Both Participants and Non-participants Attached to Tutor R and 5 Respectively

\begin{tabular}{cccccccc}
\hline \multirow{2}{*}{ Tutor } & \multirow{2}{*}{$\mathrm{t}$} & $\mathrm{df}$ & $\mathrm{Sig}$. & Mean & Std. Error & \multicolumn{2}{c}{ 95\% Confidence Interval of the Difference } \\
\cline { 7 - 8 } & & & (2-tailed) & Difference & Difference & Lower & Upper \\
\hline $\mathrm{R}$ & 2.573 & 9.895 & 0.28 & 14.651 & 5.694 & 1.946 & 27.357 \\
$\mathrm{~S}$ & 2.167 & 14.929 & .047 & 1.267 & .585 & 0.020 & 2.513 \\
\hline
\end{tabular}

2. Was there a significant difference in final exam score between learners who have participated in the pre-instructional workshop and earners who have not?

Table 5 shows the mean of the final exam score between learners who have participated in the workshop is higher (Tutor $R=35.225$ and Tutor $S=16.042$ ) compared with learners who have not participated (Tutor $R=16.393$ dan Tutor $S=8.208$ ).

Table 5. Mean Score of the Final Exam Score of Learners Who Have Participated in the Preinstructional Workshop and Learners Who Have Not

$\begin{array}{cccccc}\text { Tutor } & \text { Participation Status } & \text { N } & \text { Mean Ratio } & \text { Std. Deviation } & \text { Std. Error Mean } \\ \text { R } & \text { Yes } & 10 & 34.225 & 15.347 & 4.853 \\ & \text { No } & 42 & 16.393 & 16.332 & 2.520 \\ \text { S } & \text { Yes } & 12 & 16.042 & 7.910 & 2.283 \\ & \text { No } & 24 & 8.208 & 8.728 & 1.782\end{array}$

Table 6 shows the results of Independent Sample T test carried out on final exam score. The results show that the alpha value obtained s less than 0.05 indicating that there is a significant difference between the final score of learners who have participated in the workshop.

Table 6. Independent Sample T Test Carried Out on Online Participation Ratio for Both Participants and Non-participants Attached to Tutor R and S Respectively

\begin{tabular}{cccccccc}
\hline \multirow{2}{*}{ Tutor } & $\mathrm{t}$ & df & \multirow{2}{*}{$\begin{array}{c}\text { Sig. } \\
\text { (2-tailed) }\end{array}$} & $\begin{array}{c}\text { Mean } \\
\text { Difference }\end{array}$ & $\begin{array}{c}\text { Std. Error } \\
\text { Difference }\end{array}$ & \multicolumn{2}{c}{$\begin{array}{c}\text { 95\% Confidence Interval of } \\
\text { the Difference }\end{array}$} \\
\cline { 7 - 9 } & & & & & & Lower & Upper \\
\hline $\mathrm{R}$ & 3.312 & 50 & .002 & 18.832 & 5.686 & 7.412 & 30.252 \\
$\mathrm{~S}$ & 2.615 & 32 & .013 & 7.833 & 2.995 & 1.746 & 13.920 \\
\hline
\end{tabular}

3. Was there a significant difference in the final exam score between learners who were attached to tutor providing supplemental instruction and learner who were not?

Independent Sample T test carried out on Final Exam Score as shown in Table 7 produced an alpha value of less than 0.05 indicating that them is a significant difference between the final exam score of learners attached to tutor R (provides SI) and tutor S. 
Table 7. Independent Sample T Test carried out on Final Exam Score for learners attached to Tutor $\mathrm{R}$ and $\mathrm{S}$

\begin{tabular}{cccccccc}
\hline \multirow{2}{*}{ Tutor } & $\mathrm{t}$ & $\mathrm{df}$ & $\begin{array}{c}\text { Sig. } \\
\text { (2-tailed) }\end{array}$ & $\begin{array}{c}\text { Mean } \\
\text { Difference }\end{array}$ & $\begin{array}{c}\text { Std. Error } \\
\text { Difference }\end{array}$ & \multicolumn{2}{c}{$\begin{array}{c}95 \% \text { Confidence Interval } \\
\text { of the Difference }\end{array}$} \\
\cline { 7 - 9 } & & & & & Lower & Upper \\
\hline Final Exam Score & 3.186 & 80.558 & .002 & 9.195 & 2.886 & 3.452 & 14.938 \\
\hline
\end{tabular}

4. Was there a difference in the $\mathrm{COI}$ mean score between learners who have participated and undergone the supplemental instruction and those who have not?

From Figure 2 it is noted that the mean $\mathrm{COI}$ score for Tutor $\mathrm{R}$ (with $\mathrm{SI}$ ) is generally higher than Tutor $\mathrm{S}$ in teaching and cognitive presence but marginally in social presence.

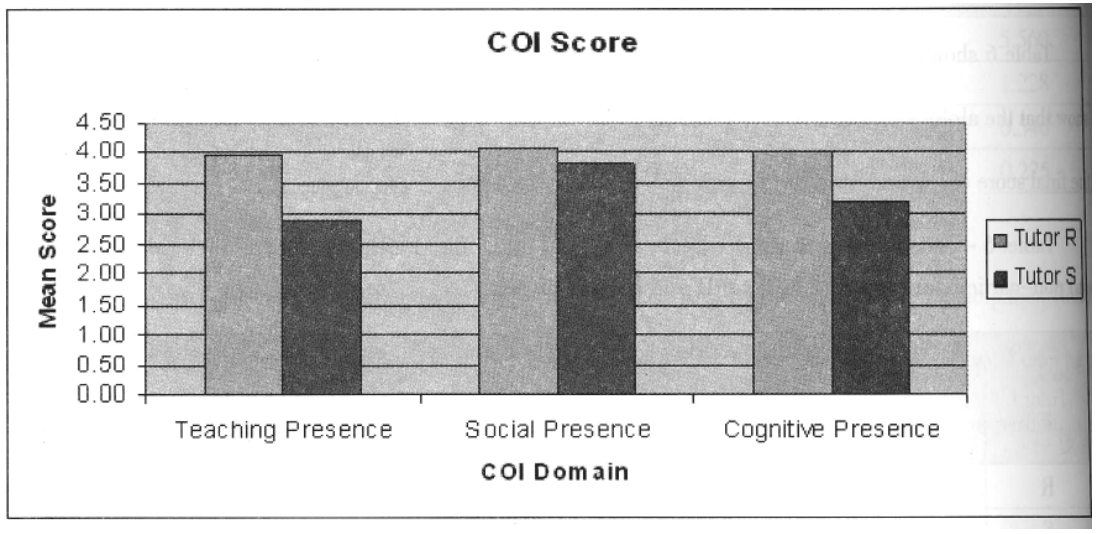

\section{CONCLUSION}

The pre-instructional workshop which introduces the basic mathematics and technology has an impact on learners' online participation and final exam score. Learners attached to tutor $R$, who have participated in the workshop and SI showed higher online participation ratio and final exam score compared with learners who have not. Those who have participated in the workshop irrespective of tutors also showed a higher final exam score compared with those who have not. The mean $\mathrm{COI}$ score obtained show that the workshop and supplemental instruction have impacts on teaching, social and cognitive presence, which form the Collaborative Online Learning (COL).

This workshop conducted as part of the orientation program and the extended coaching via online which act as supplemental instruction (SI), have proven to provide academic assistance to these learners to succeed (Hodges, 2001). The result obtained in this research support the study conducted by Dash (2004) and Russell (2006) that face-to-face workshop does improve the achievement of the learner significantly. The results also indicate that the content provided during the workshop and the continuous support provided by the tutor via online can significantly increase the learners' online forum participation and examination results. This collaborates with Lotze's (2002) findings that it is imperative to introduce both the basic concepts of mathematics and equation editor software skills as a pre-tutorial session to enhance learning of mathematics via online. 


\section{REFERENCES}

Abtar, K. (2004). The effectiveness of online discussion forum al OUM. Research Paper funded by OUM. Kuala Lumpur: Open University Malaysia.

Dasgupta, S. (2006). Encyclopedia of virtual communities and technologies. IGI Publishing. In Books24x7. OUM Digital Collections.

Dash, N.K. (2004). Impact of face-to-face workshop on the achievement of distance teacher trainees. Retrieved: February 15, 2008 from http://www.col.org/pcf3/Papers/PDFs/ Das_Nirod_Kumar.pdf.

Doty, C.S. (2003). Supplemental instruction national data summary. Kansas City: University of Missouri.

Engelbrecht \& Harding. (2004). Technologies involved in the teaching of undergraduate mathematics on the web. Retrieved: February 18, 2008 from http://ridcully.up.ac.za/muti/technologies.pdf.

Fadzil, M. (2005). Success factors for e-learning implementation. Papers presented during the Seminar on Trends \& Developments in Distance Education \& E-Learning on June 30, 2005 at Hotel UITM, Shah Alam, Selangor.

Garrison, D.R., Anderson, T., \& Archer, W. (2000). Critical inquiry in a text-based environment: Computer conferencing in higher education. The Internet and Higher Education, 2 (23), 87-105.

Hodges, R. (2001). Encouraging high-risk student participation in tutoring and supplemental instruction. Journal of Development Education, 24 (3), p. 2-9.

Hofmann, J. (2004). Live and online: Tips, techniques, and ready-to-use activities for the virtual classroom. New Jersey: Pfeiffer. In Books24x7. OUM Digital Collection.

Lotze, C.D. (2002). Online Mathematics and Statistics tutor effectiveness and implementation issues. Ph.D. Thesis. American University, Washington DC.

Martin, D.C. \& Arendale, D. (1993). Foundation and theoretical framework for SI. (2 ${ }^{\text {nd }}$ edn.). Columbia: National Resources Center for the Freshman Year Experience and Students in Transition.

Neuhauser, C. (2002). Learning style and effectiveness of online and face-to-face instruction. The American Journal of Distance Education, 16 (2), p.990-113.

Ng. R. (2008). Online discussion forum: What tutors and learners do and how the do it? An analysis of Management Mathematics course and Community of Inquiry concept. Paper presented at the LYICT 2008 Conference, Saujana Kuala Lumpur Hotel, Kuala Lumpur, Malaysia from 7-11 July, 2008.

Ng. R \& Wagner, K. (2007). Impact of COL on the participation behavioral pattern of learners and tutors in the online discussion forum. Paper presented at the SEAAIR 2007 Conference held at Assumption University, Bangkok, Thailand from September 4-6, 2007.

Phelps, J.M. (2005). Supplemental instruction in a community college developmental mathematics curriculum: a phenomenological study of learning experiences. Ph.D. Thesis, University of Central Florida, Florida.

Pillay, Irving, \& Tones. (2007). Validation of the diagnostic tool for assessing tertiary students' readiness for online learning. Higher Education Research \& Development, 26 (2), p.217-234. 
Russell, T.L. (2001). The no significant difference phenomenon: $A$ comparative research annotated bibliography on technology for distance education. Montgomery: International Distance Education Certification Center.

Rusell, T.L. (2005). No significant difference phenomenon. Retrieved: February 15, 2008. from http://nosignificantdifference.wcet.info/index.asp.

Ryan, W.J. (2001). Comparison of student performance and attitude in a lecture class to student performance and attitude in a telecourse and a web-based class. Ph.D. Thesis. Florida: Nova Southeastern University.

Tatum, B.D. (2000). The ABC approach to creating climates of engagement on diverse campuses. Liberal Education, 86 (40), p.22-29.

Weems, G.H. (2002). Comparison of beginning algebra taught onsite versus online. Journal of Developmental Education, 26 (1), p.10-18. 